\title{
Circulating tumor cells in lung cancer are prognostic and predictive for worse tumor response in both targeted- and chemotherapy
}

\author{
Menno Tamminga ${ }^{1}$, Sanne de Wit ${ }^{2}$, Ed Schuuring ${ }^{3}$, Wim Timens ${ }^{3}$, Leon W. M. M. Terstappen ${ }^{2}$, \\ T. Jeroen N. Hiltermann ${ }^{1}$, Harry J. M. Groen ${ }^{1}$ \\ ${ }^{1}$ Department of Pulmonary Diseases, University Medical Center Groningen, University of Groningen, Groningen, The Netherlands; ${ }^{2}$ Department \\ of Medical Cell BioPhysics, Faculty of Sciences and Technology, University of Twente, Enschede, The Netherlands; ${ }^{3}$ Department of Pathology and \\ Medical Biology, University Medical Center Groningen, University of Groningen, Groningen, The Netherlands \\ Contributions: (I) Conception and design: M Tamminga, S de Wit, LW Terstappen, TJN Hiltermann, HJ Groen; (II) Administrative support: LW \\ Terstappen, HJ Groen; (III) Provision of study materials or patients: E Schuuring, W Timens, TJN Hiltermann, HJ Groen; (IV) Collection and \\ assembly of data: M Tamminga, S de Wit, E Schuuring, W Timens; (V) Data analysis and interpretation: M Tamminga, TJN Hiltermann, HJ Groen; \\ (VI) Manuscript writing: All authors; (VII) Final approval of manuscript: All authors. \\ Correspondence to: Prof. Dr. Harry J. M. Groen. Department of Pulmonary Diseases, University Medical Center Groningen, University of Groningen, \\ Hanzeplein 1, 9713 GZ Groningen, The Netherlands. Email: h.j.m.groen@umcg.nl.
}

Background: It is unknown whether the presence of circulating tumor cells (CTC), a known prognostic factor, influences treatment outcome. We investigated whether baseline CTC in non-small cell lung cancer (NSCLC) patients treated with tyrosine kinase inhibitors (TKI) or chemotherapy was associated with response to therapy.

Methods: We included consecutive advanced NSCLC patients, stratified by therapy. Before treatment the number of CTC was measured by CellSearch. Tumor response rates, progression free survival (PFS) and overall survival (OS) in patients with and without CTC at baseline were compared.

Results: We included 86 patients (34 treated by TKI). Response rates of patients with CTC were lower than in patients without CTC $(\mathrm{OR}=0.22, \mathrm{P}<0.01$, adjusted for performance score and smoking status). In both treatment groups, the difference in response rates between patients with and without CTC was similar (TKI response: $25 \%$ with CTC versus $73 \%$ without CTC, chemotherapy response: $35 \%$ versus $51 \%$ respectively, interaction $\mathrm{P}=0.17)$. CTC was associated with a worse $\mathrm{PFS}$ [hazard ratio $(\mathrm{HR})=2.0,95 \%$ confidence interval (CI): 1.2-3.2, $\mathrm{P}=0.01]$ and $\mathrm{OS}(\mathrm{HR}=1.7,95 \% \mathrm{CI}: 1.1-2.8, \mathrm{P}=0.03$ ) after adjustment for performance score and stage. The association remained significant after adding tumor response to the model (PFS: HR =1.9, 95\% CI: 1.0-3.0, P=0.01, OS: HR =1.6, 95\% CI: 1.0-2.6, P=0.05). No significant interaction between CTC presence and therapy was observed ( $\mathrm{P}=0.42$ for $\mathrm{PFS}$ and $\mathrm{P}=0.83$ for OS).

Conclusions: Presence of CTC in advanced NSCLC patients is associated with low response rates, shorter PFS and OS, independent of the received therapy.

Keywords: Circulating tumor cell (CTC); non-small cell lung cancer (NSCLC); tyrosine kinase inhibitors (TKI); liquid biopsy; chemotherapy

Submitted Jul 01, 2019. Accepted for publication Sep 23, 2019.

doi: $10.21037 /$ tlcr.2019.11.06

View this article at: http://dx.doi.org/10.21037/tlcr.2019.11.06

\section{Introduction}

Lung cancer accounts for $13 \%$ of new cancer cases diagnosed and is responsible for $19 \%$ of all cancer related deaths, partly explained by the fact that most lung cancer have advanced disease at the time of diagnosis (1).

New cancer drugs, such as tyrosine kinase inhibitors (TKI) targeting EGFR, ALK, ROS-1, RET and BRAF mutations, and checkpoint inhibitors have markedly 
improved the prognosis for a select group of non-small cell lung cancer (NSCLC) patients (2,3). Unfortunately, resistance towards targeted therapies usually emerges within one year $(4,5)$. Therefore it becomes of great value to monitor the disease via minimally invasive techniques such as circulating tumor cells (CTC) derived from the bloodstream, as treatment may be adjusted at the earliest moment.

CTC have been proven to be an important and independent prognostic marker in several cancers, including lung cancer (6-14). The presence of CTC may be a reflection of the metastatic tumor burden or tumor invasiveness, explaining the strong association with overall survival (OS) $(10,12,13)$. However, whether baseline CTC may predict tumor responses to therapy, irrespective of their prognostic value has not been investigated.

We hypothesized that CTC at baseline is an indicator for worse tumor response in advanced NSCLC patients treated with TKIs or chemotherapy. In addition, response rates to chemotherapy and targeted therapy were compared between patients with and without CTC to determine whether there are differences in treatment effectivity.

\section{Methods}

\section{Patient inclusion}

Consecutive patients with histologically proven bulky stage III or stage IV NSCLC, treated with chemotherapy or TKI, were eligible for inclusion in this exploratory prospective single center cohort study. The study was approved by the Medical Ethical Committee (NTR5540) and informed consent was obtained from all patients.

\section{Enumeration and scoring of CTC}

Before the start of treatment (baseline) $7.5 \mathrm{~mL}$ of whole blood was drawn into a CellSave blood collection tube (Menarini Silicon Biosystems, Huntingdon Valley PA, USA) and processed for CTC enumeration by the CellSearch $^{\circledR}$ Circulating Tumor Cell Kit within 96 hours. CTC were determined according to previously published protocols $(11,14)$. In short, cells were separated based on the expression of the epithelial cell adhesion molecule (EpCAM), by means of magnetic beads. Afterwards cells that did not express CD45 and were positive for the expression of EpCAM, cytokeratin (8/18/19) and DAPI were considered to be CTC.
For NSCLC there is no predefined cut-off for CTC counts. Previous studies in NSCLC have used a value of 1 or 2 CTC per $7.5 \mathrm{~mL}(8,9,15)$. We decided to use the lowest cut-off value of 1 CTC per $7.5 \mathrm{~mL}$ blood (CTC presence).

\section{Clinical assessment and retrievement of clinical data}

Clinical assessments were done by the treating physician blinded for CTC scores. Molecular predictive testing was performed on pretreatment tissue biopsies using an in-house panel (version PGMv001) on the IonTorrent platform covering 11 clinically relevant genes (namely ALK, BRAF, EGFR, ERBB2, GNA11, GNAQ, KIT, KRAS, NRAS, PDGFRA and PIK3CA), and by means of FISH and immunohistochemistry on ALK, ROS1 and RET for adenocarcinoma patients, while amplification of FGFR1 was measured in squamous cell carcinoma patients $(16,17)$. Molecular profiles of late-stage adenocarcinoma of the lung were retrieved from the database of the Laboratory of Molecular Pathology at the UMCG.

\section{Therapy response}

The response to treatment was measured after 6 weeks according to the Revised Response Evaluation Criteria In Solid Tumors version 1.1 (RECIST 1.1) denoting tumor response as progressive disease (PD), stable disease (SD), partial response (PR) and complete response (CR) (18). Patients with a PR or CR were classified as responders, while PD and SD were denoted as non-responders in the analyses.

Progression free survival (PFS) (time from start of treatment until disease progression occurred as defined by RECIST 1.1), and OS (time until death after start of treatment) were retrieved from the patients file. Follow up was completed in November 2018, at which time 9 patients were still alive, all having a follow up of at least 42 months.

\section{Statistical analysis}

Descriptive analyses were performed for all patients and by therapy group (TKI versus chemotherapy). Differences between treatment groups were tested by means of Fisher's exact and Mann-Whitney $U$ tests.

Logistic regression was used to determine differences in response rates between patients with and without CTC, while Cox regression analysis was used to assess differences 
in survival.

Multivariable models were used, with covariables selected in a backward conditional method. In short, all clinical parameters (age, gender, PS, smoking status, stage, mutations and therapy line) were included in the original model, after which a selection was made. Covariables with $\mathrm{P}>0.157$ (based on the Akaike information criterion) were excluded, starting with the highest $\mathrm{P}$ value.

When CTC were significantly related to tumor response and survival, response would be incorporated as a covariable in the survival model to evaluate whether the relationship with response explained the difference in survival.

A sensitivity analysis (i.e., repeating the logistic regression and Cox regression analyses with a more homogenous population by using more stringent inclusion criteria) was performed including only adenocarcinoma patients. This was done to exclude disproportionate effects of other histological subtypes, considering that TKI treatment is mostly given to patients with adenocarcinoma.

If CTC were significantly associated with response or survival, the same model would be repeated, with the inclusion of an interaction term, composed of CTC presence and therapy group. This was done to evaluate whether the correlation of CTC with response or survival differed depending on the treatment that was given. If the interaction term was significant, the response rates or survival time for patients with and without CTC were different depending on the given therapy.

Outcomes are given as odds ratio (OR) for the logistic regressions (a value below 1 corresponds to a worse response rate), and hazard ratios (HR) for the Cox regression analyses (a value above 1 corresponds with a shorter survival). An effect is considered significant when $\mathrm{P}<0.05$ in a two-sided test. All analyses are performed using SPSS version 23.

\section{Power analysis}

As this is the first study exploring the possibility that the presence of CTC lowers tumor response rates, we assumed that response rates would be twice as high for patients without CTC as they would be for patients with CTC.

For targeted therapy the response rate for patients without CTC was assumed to be $70 \%$, and for patients with CTC $35 \%$. Assuming $\alpha=0.05$ and $\beta=0.8$, we would need to include 32 patients in the targeted therapy group. For the patients treated with chemotherapy we assumed that $60 \%$ would have a partial or CR when no CTC were detected.
Therefore we would need 56 patients in the chemotherapy group.

\section{Results}

\section{Patient characteristics}

Eighty-six patients were included in this prospective study. Thirty-four received TKI. Baseline patient characteristics show that stage of disease, smoking, histology and DNA aberrations differed between the TKI and chemotherapy group (Table 1). Patients in the chemotherapy group received cisplatin $(\mathrm{n}=30,58 \%)$ or carboplatin $(\mathrm{N}=22$, $42 \%$ ) combined with either pemetrexed, gemcitabine or paclitaxel. Patients receiving TKI were mostly treated with erlotinib for EGFR mutations ( $\mathrm{N}=11,32 \%)$ or dabrafenib for BRAF mutations ( $N=7,21 \%)$. Specific information on TKI treatment and respective DNA aberrations is provided in Table S1. Tumor response and survival were not different between both groups (Table 2). Patients in the chemotherapy group mostly had immunotherapy on disease progression, while TKI patients did not. The presence of CTC and their number did not differ between treatment groups. No significant differences were identified between patients with and without CTC (Table S2).

There were seven patients with $\geq 5 \mathrm{CTC} / 7.5 \mathrm{~mL}$ blood (4 received TKI and 3 chemotherapy). All of these patients had PD at 6 weeks and died within 3 months.

\section{Tumor response rates}

Tumor response rates at six weeks were significantly lower in patients who had CTC detected in $7.5 \mathrm{~mL}$ of blood (31\% responding) compared to patients without CTC (61\% responding, $\mathrm{P}=0.01$ ). After adjustment for $\mathrm{PS}$ and smoking status, the presence of CTC remained significantly associated with worse tumor response $[\mathrm{OR}=0.22,95 \%$ confidence interval (CI): $0.07-0.65, \mathrm{P}<0.01]$. The sensitivity analysis including only patients with adenocarcinoma showed a similar relation $(\mathrm{OR}=0.16,95 \% \mathrm{CI}$ : $0.05-0.6$, $\mathrm{P}<0.01)$.

Stratified for treatment group CTC were predictive of lower response rates for both TKI treatment $(\mathrm{OR}=0.04$, 95\% CI: $0.00-0.62, \mathrm{P}=0.02)$ and chemotherapy $(\mathrm{OR}=0.23$, 95\% CI: $0.05-0.97, \mathrm{P}=0.05)$ in a multivariable analysis.

The interaction term between presence of CTC and treatment was not significant (TKI response: $25 \%$ with CTC versus $73 \%$ without CTC, chemotherapy response: 
Table 1 Baseline characteristics of 86 advanced NSCLC patients who were treated with either chemotherapy or tyrosine kinase inhibitors

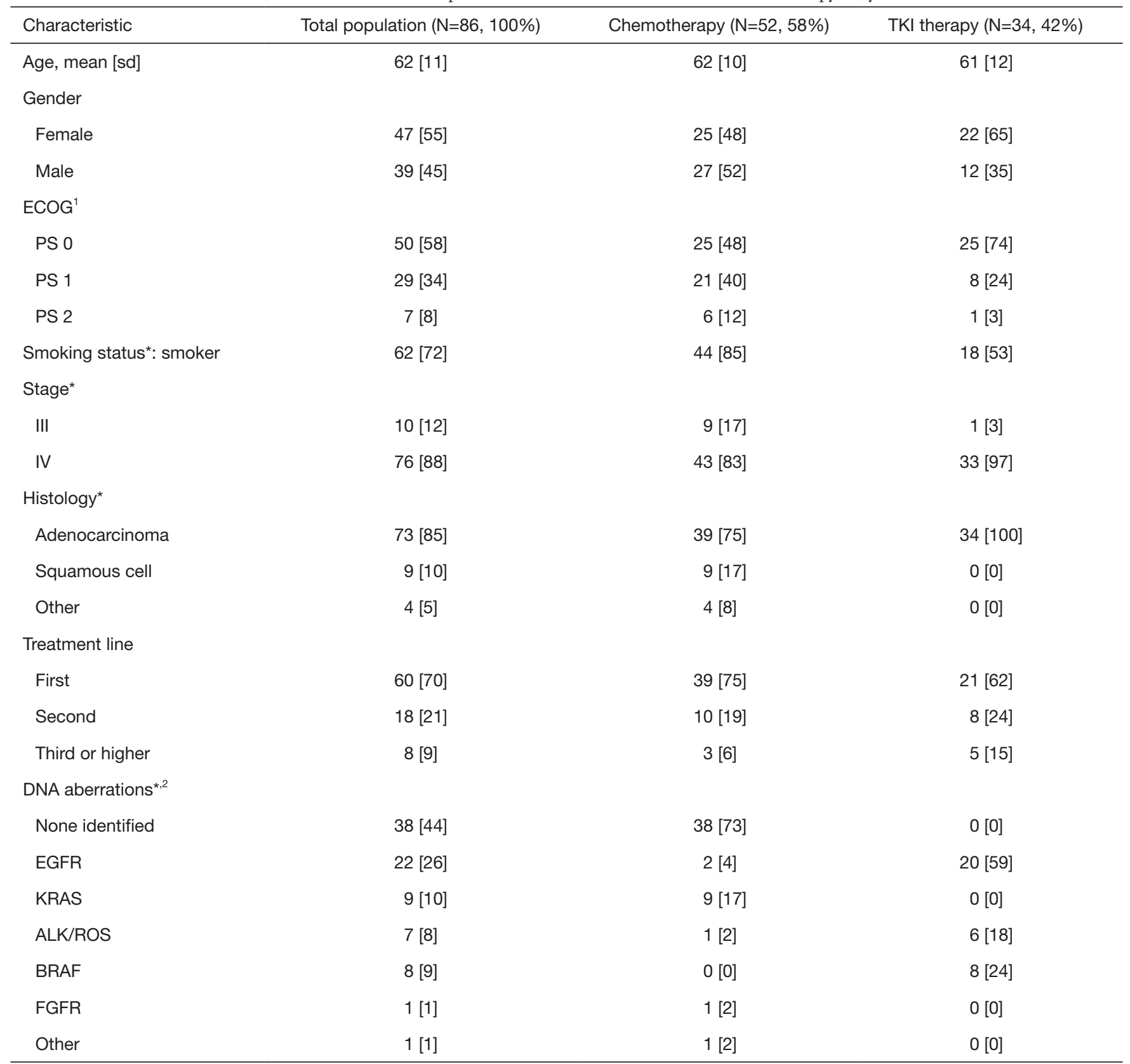

${ }^{1}$, Eastern Cooperative Oncology Group Performance Score; ${ }^{2}$, Molecular profiling performed on tissue biopsy of adenocarcinoma using a NGS multigene panel including TKI-targetable mutations, FISH for ALK, ROS1 and RET rearrangements and IHC for ALK expression on adenocarcinoma. Squamous cell carcinoma was tested for FGFR1 amplifications; *, covariable was significantly different between treatment groups $(\mathrm{P}<0.05)$. NSCLC, non-small cell lung cancer.

$35 \%$ versus $51 \%$ respectively, interaction $\mathrm{P}=0.27$. Figure 1 ).

\section{Survival and CTC}

As shown in Figure 2, patients with CTC had a median PFS of 3.3 months (TKI: 2.3, chemotherapy: 4.2), and an OS of 5.2 months (TKI: 2.5 months, chemotherapy: 6.1 months). For patients without CTC median PFS was 8.0 months (TKI: 8.4, chemotherapy: 5.7) and OS was 12.1 months (TKI: 12.1, chemotherapy: 11.8). 
Table 2 Response, survival and circulating tumor cell counts of 91 advanced NSCLC patients treated with either chemotherapy or tyrosine kinase inhibitors

\begin{tabular}{llll}
\hline Characteristic & Total population $(\mathrm{n}=86,100 \%)$ & Chemotherapy $(\mathrm{n}=52,60 \%)$ & TKI therapy $(\mathrm{n}=34,40 \%)$ \\
\hline CTC detected & & & \\
Median [range] & $0[0-151]$ & $0[0-29]$ & $0[0-151]$ \\
Patients with CTC & $29[34]$ & $17[33]$ & $12[35]$ \\
CTC $=1$ & $7[8]$ & $5[10]$ & $2[6]$ \\
CTC $=2-4$ & $15[17]$ & $9[17]$ & $6[17]$ \\
CTC $>5$ & $7[8]$ & $3[6]$ & $4[12]$ \\
Tumor response & & & $3[9]$ \\
Complete response & $6[7]$ & $3[6]$ & $16[47]$ \\
Partial response & $37[43]$ & $21[40]$ & $3[9]$ \\
Stable disease & $13[15]$ & $10[19]$ & $12[35]$ \\
Progressive disease & $30[35]$ & $18[35]$ & $8[0-45]$ \\
Median PFS, months [range] & $5[0-55]$ & $5[0-55]$ & $11[0-53]$ \\
Median OS, months [range] & $11[0-55]$ & $9[1-55]$ & .
\end{tabular}

${ }^{1}$, Revised Response Evaluation Criteria In Solid Tumor v1.1. No significant differences between patient groups were observed. NSCLC, non-small cell lung cancer; CTC, circulating tumor cell; PFS, progression free survival; OS, overall survival.

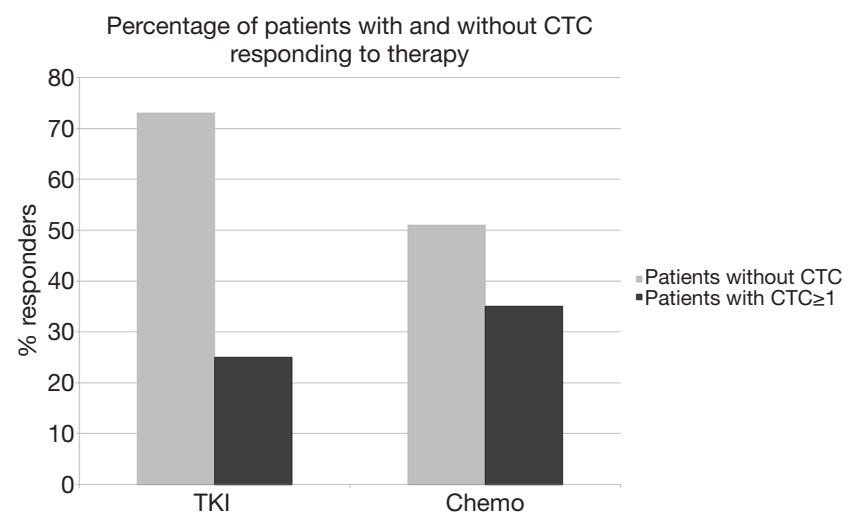

Figure 1 Percentage responders of non-small cell lung cancer patients stratified for their given treatment [chemotherapy or tyrosine kinase inhibitors (TKI)] and circulating tumor cell (CTC) presence at baseline.

The presence of CTC was associated with a worse PFS ( $\mathrm{HR}=2.0,95 \% \mathrm{CI}: 1.2-3.2, \mathrm{P}=0.01)$ and $\mathrm{OS}(\mathrm{HR}=1.7$, $95 \% \mathrm{CI}: 1.1-2.8, \mathrm{P}=0.03)$. The difference in survival caused by the presence of CTC did not differ between treatment groups (interaction $\mathrm{P}=0.56$ for $\mathrm{PFS}$ and $\mathrm{P}=0.65$ for $\mathrm{OS}$ ). $\mathrm{PS}$ and stage remained significant covariables in the model.

When correcting for response to treatment in the multivariable model, the presence of CTC remained significantly associated with worse PFS (HR CTC $=1.9$, 95\% CI: $1.0-3.0, \mathrm{P}=0.01$ ) and OS (CTC HR $=1.6,95 \%$ CI: $1.0-2.6, \mathrm{P}=0.05)$.

The sensitivity analyses with only adenocarcinoma patients showed similar results (PFS: $\mathrm{HR}=1.9,95 \%$ CI: $1.1-$ 3.3, $\mathrm{P}=0.02$, OS: $\mathrm{HR}=2.1,95 \%$ CI: $1.2-3.6, \mathrm{P}<0.01$ ), even when taking response into account ( $\mathrm{PFS}$ : $\mathrm{HR}=1.8,95 \% \mathrm{CI}$ : 1.0-3.0, $\mathrm{P}=0.04$, OS: $\mathrm{HR}=1.8,95 \%$ CI: $1.1-3.1, \mathrm{P}=0.03$ ).

\section{Discussion}

In this study we showed that the presence of CTC before therapy is a risk factor for worse tumor response rates and survival in advanced NSCLC, irrespective of treatment. The response rate to TKI treatment is severely lowered in patients with CTC.

CTC have shown to be prognostic for lung cancer previously (6-14). Additionally, an increase in CTC numbers during treatment is associated with worse response and shorter PFS and OS $(7,19,20)$. However, this is the first study reporting that the presence of CTC at baseline in advanced NSCLC patients is associated with worse response to therapy, and that this is independent of the given therapy. 
A

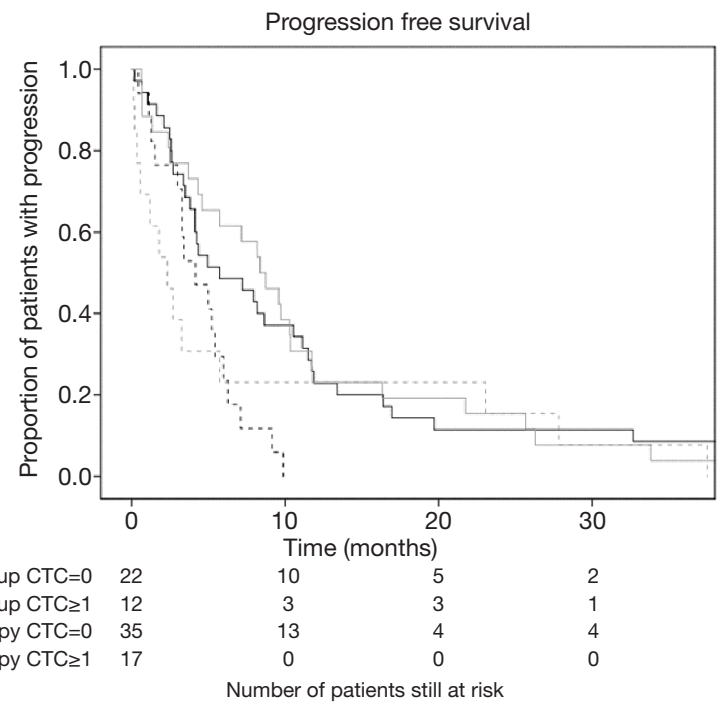

B

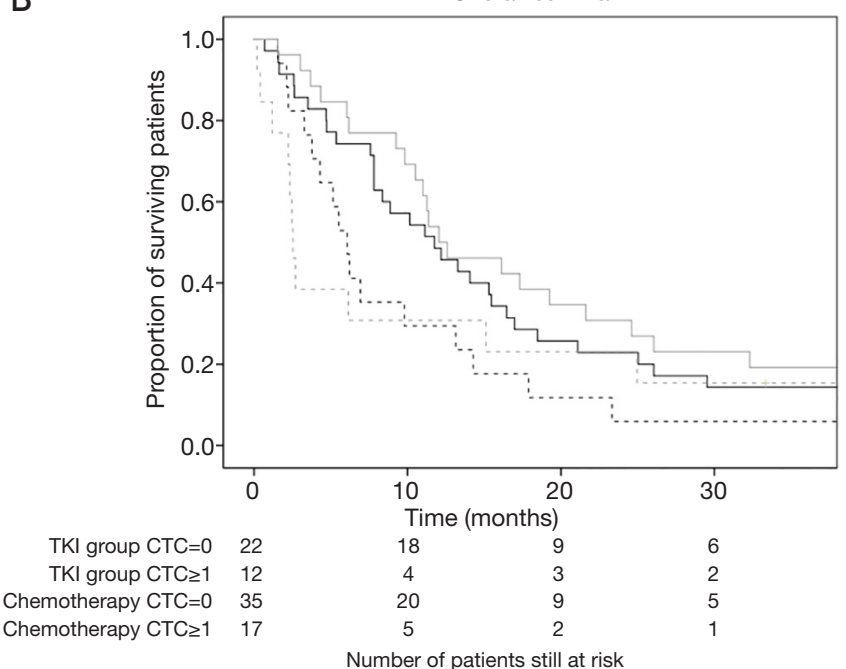

Figure 2 Progression-free and overall survival of 86 advanced non-small cell lung cancer patients, stratified for circulating tumor cell presence at baseline and therapy. Figures show progression free survival (PFS) (A) and overall survival (OS) (B). Patients were stratified for the presence of circulating tumor cells (CTC) at baseline (whole line: $\mathrm{CTC}=0$, dashed line: $\mathrm{CTC} \geq 1$ ) and for given therapy [chemotherapy: black, tyrosine kinase inhibitor (TKI): grey]. Patients with CTC had significantly shorter PFS and OS compared to patients without CTC (median PFS of 3.3 versus 8.0 months respectively, $\log$ rank test $\mathrm{P}<0.01$, and median OS of respectively 5.2 and 12.6 months, $\log$ rank test $\mathrm{P}<0.01$ ). CTC decreased survival in both treatments groups. Median PFS and OS of patients without CTC receiving TKI was 9.6 and 16.1 months respectively, while for patients without CTC receiving chemotherapy it was 5.7 and 11.8 months respectively. Median PFS and OS of patients with CTC receiving TKI was 1.8 and 2.5 months respectively and for patients with CTC receiving chemotherapy it was 4.2 and 6.1 months respectively.

The lower response rate in those with CTC could be due to epithelial to mesenchymal transition (EMT) that tumor cells and CTC may undergo, inducing increased expression of genes related to resistance to chemotherapy, as seen in possible cancer stem cells $(21,22)$. Other possibilities are that CTC indicate more tumor burden influencing the physical state of a patient, causing a decreased drug tolerability, and/or that CTC are associated with a more aggressive tumor, leading to less responsiveness to treatment and shorter survival $(10,12,13)$.

Alternative liquid biopsies which can predict the response to targeted therapy have been investigated. Circulating tumor DNA (ctDNA), may be shed from the original tumor or its metastases and is another option besides CTC as a liquid biopsy (23-26). As TKI's target aberrant proteins or receptors, their corresponding DNA mutations can be detected in the plasma, foregoing invasive biopsies.

While mutations can also be identified in CTC, ctDNA can be detected in a larger proportion of patients and outperforms mutation detection in CTC $(26,27)$. Yet ctDNA has been shown to have no additional predictive value compared to mutations detected in the tumor biopsy like CTC in our study (28-30). Additionally, when enough CTCs are isolated functional testing can be performed. Moreover, one can measure the tumor heterogeneity and the potential propensity characteristics of the tumor.

Currently, CTC are detected in only $30-35 \%$ of patients with advanced NSCLC. However, they can be obtained in a larger proportion of patients in greater numbers when an increased blood volume obtained through leukapheresis is analyzed $(31,32)$. In the apheresis product CTC are more concentrated, allowing easier detection and further functional analysis. Already, differences in the expression of programmed death ligand 1 (PD-L1) and epithelial cell adhesion molecule (EpCAM) have been identified on CTC, with different consequences for prognosis $(11,15,33,34)$. But whether this can be used to improve the association of CTC with response is still unknown.

For our study, we used a real life patient cohort of 86 patients with advanced NSCLC. Despite the small number and heterogeneity, CTC were still significantly associated with lower response, even with a cut off value of 
$\mathrm{CTC} \geq 1$, indicating their profound influence on outcome.

While for other tumors a cut off value of $\geq 5$ CTC is recommended, in NSCLC a lower cut off is used due to the low CTC counts identified (7). While cut off values for NSCLC differ between investigators, they are often 1 or 2 CTC in $7.5 \mathrm{~mL}$ of blood $(8,9,11,15,20)$. We decided to use CTC $\geq 1$ as a cut off based on previous studies and to maximize the amount of patients that were CTC positive $(8,9)$.

\section{Conclusions}

Patients who had targetable mutations and were treated with TKIs had CTC present in similar proportions to patients without targetable mutations treated with chemotherapy (31\% and 35\% respectively). The presence of CTC was associated with worse tumor response rates and survival for both TKI and chemotherapy.

\section{Acknowledgments}

Funding: This work was supported by the Cancer-ID consortium in which the authors participate. CancerID has received support from the Innovative Medicines Initiative (IMI) Joint Undertaking under grant agreement (No. 115749). Its resources are composed of financial contribution from the European Union's Seventh Framework Program (FP7/2007-2013) and EFPIA companies' in-kind contribution. The MCBP department of the University of Twente received the CellSearch kits from Janssen Diagnostics as part of a collaborative research agreement.

\section{Footnote}

Conflicts of Interest: The authors have no conflicts of interest to declare.

Ethical Statement: The authors are accountable for all aspects of the work in ensuring that questions related to the accuracy or integrity of any part of the work are appropriately investigated and resolved. The study was approved by the Medical Ethical Committee (NTR5540) and informed consent was obtained from all patients.

\section{References}

1. Siegel RL, Miller KD, Jemal A. Cancer statistics, 2016. CA Cancer J Clin 2016;66:7-30.

2. Topalian SL, Hodi FS, Gettinger SN, et al. Safety, Activity, and Immune Correlates of Anti-PD-1 Antibody in Cancer. N Engl J Med 2012;366:2443-54.

3. Rizvi NA, Hellmann MD, Snyder A, et al. Mutational landscape determines sensitivity to PD-1 blockade in nonsmall cell lung cancer. Science 2015;348:124-8.

4. Gainor JF, Dardaei L, Yoda S, et al. Molecular Mechanisms of Resistance to First- and Second- Generation ALK Inhibitors in ALK-Rearranged Lung Cancer. Cancer Discov 2016;6:1118-33.

5. Sequist LV, Waltman BA, Dias-santagata D, et al. Genotypic and Histological Evolution of Lung Cancers Acquiring Resistance to EGFR Inhibitors. Sci Transl Med 2011;3:75ra26.

6. Cristofanilli M. Circulating Tumor Cells: A Novel Prognostic Factor for Newly Diagnosed Metastatic Breast Cancer. J Clin Oncol 2005;23:1420-30.

7. Coumans FAW, Ligthart ST, Terstappen LWMM. Interpretation of Changes in Circulating Tumor Cell Counts. Transl Oncol 2012;5:486-91.

8. Hofman V, Ilie MI, Long E, et al. Detection of circulating tumor cells as a prognostic factor in patients undergoing radical surgery for non-small-cell lung carcinoma: comparison of the efficacy of the CellSearch AssayTM and the isolation by size of epithelial tumor cell method. Int J Cancer 2011;129:1651-60.

9. Punnoose EA, Atwal S, Liu W, et al. Evaluation of circulating tumor cells and circulating tumor DNA in nonsmall cell lung cancer: Association with clinical endpoints in a phase II clinical trial of pertuzumab and erlotinib. Clin Cancer Res 2012;18:2391-401.

10. Hiltermann TJN, Pore MM, van den Berg A, et al. Circulating tumor cells in small-cell lung cancer: A predictive and prognostic factor. Ann Oncol 2012;23:2937-42.

11. de Wit S, Rossi E, Weber S, et al. Single tube liquid biopsy for advanced non- small cell lung cancer Single tube liquid biopsy for advanced non- small cell lung cancer. Int J Cancer 2019;144:3127-37.

12. Budd GT, Cristofanilli M, Ellis MJ, et al. Circulating tumor cells versus imaging - Predicting overall survival in metastatic breast cancer. Clin Cancer Res 2006;12:6403-9.

13. De Giorgi U, Valero V, Rohren E, et al. Circulating tumor cells and bone metastases as detected by FDG-PET/ CT in patients with metastatic breast cancer. Ann Oncol 2010;21:33-9.

14. Cristofanilli M, Budd GT, Ellis MJ, et al. Circulating Tumor Cells, Disease Progression, and Survival in Metastatic Breast Cancer. N Engl J Med 2004;351:781-91. 15. Krebs MG, Hou JM, Sloane R, et al. Analysis of circulating 
tumor cells in patients with non-small cell lung cancer using epithelial marker-dependent and -independent approaches. J Thorac Oncol 2012;7:306-15.

16. van der Wekken AJ, Pelgrim R, T Hart N, et al. Dichotomous ALK-IHC is a better predictor for ALK inhibition outcome than traditional ALK-FISH in advanced non-small cell lung cancer. Clin Cancer Res 2017;23:4251-8.

17. Boonstra PA, ter Elst A, Tibbesma M, et al. A single digital droplet PCR assay to detect multiple KIT exon 11 mutations in tumor and plasma from patients with gastrointestinal stromal tumors. Oncotarget 2018;9:13870-83.

18. Eisenhauer EA, Therasse P, Bogaerts J, et al. New response evaluation criteria in solid tumours: Revised RECIST guideline (version 1.1). Eur J Cancer 2009;45:228-47.

19. Muinelo-Romay L, Vieito M, Abalo A, et al. Evaluation of circulating tumor cells and related events as prognostic factors and surrogate biomarkers in advanced NSCLC patients receiving first-line systemic treatment. Cancers (Basel) 2014;6:153-65.

20. Krebs MG, Sloane R, Priest L, et al. Evaluation and prognostic significance of circulating tumor cells in patients with non-small-cell lung cancer. J Clin Oncol 2011;29:1556-63.

21. Papadaki MA, Stoupis G, Theodoropoulos PA, et al. Circulating tumor cells with stemness and epithelial-tomesenchymal transition features are chemoresistant and predictive of poor outcome in metastatic breast cancer. Mol Cancer Ther 2019;18:437-47.

22. Chebouti I, Kasimir-Bauer S, Buderath P, et al. EMTlike circulating tumor cells in ovarian cancer patients are enriched by platinum-based chemotherapy. Oncotarget 2017;8:48820-31.

23. Zheng D, Ye X, Zhang MZ, et al. Plasma EGFR T790M ctDNA status is associated with clinical outcome in advanced NSCLC patients with acquired EGFR-TKI resistance. Sci Rep 2016;6:20913-9.

24. Marchetti A, Palma JF, Felicioni L, et al. Early Prediction of Response to Tyrosine Kinase Inhibitors by

Cite this article as: Tamminga M, de Wit S, Schuuring E, Timens W, Terstappen LW, Hiltermann TJN, Groen HJ. Circulating tumor cells in lung cancer are prognostic and predictive for worse tumor response in both targeted- and chemotherapy. Transl Lung Cancer Res 2019;8(6):854-861. doi: 10.21037/tlcr.2019.11.06
Quantification of EGFR Mutations in Plasma of NSCLC Patients. J Thorac Oncol 2015;10:1437-43.

25. Guibert N, Pradines A, Farella M, et al. Monitoring KRAS mutations in circulating DNA and tumor cells using digital droplet PCR during treatment of KRAS-mutated lung adenocarcinoma. Lung Cancer 2016;100:1-4.

26. Freidin MB, Freydina DV, Leung M, et al. Circulating tumor DNA outperforms circulating tumor cells for KRAS mutation detection in thoracic malignancies. Clin Chem 2015;61:1299-304.

27. Guibert N, Pradines A, Casanova A, et al. Detection and monitoring of the BRAF mutation in circulating tumor cells and circulating tumor DNA in BRAF-mutated lung adenocarcinoma. J Thorac Oncol 2016;11:e109-12.

28. Luo J, Shen L, Zheng D. Diagnostic value of circulating free DNA for the detection of EGFR mutation status in NSCLC: A systematic review and meta-analysis. Sci Rep 2014;4:6269.

29. Oxnard GR, Thress KS, Alden RS, et al. Association between plasma genotyping and outcomes of treatment with osimertinib (AZD9291) in advanced non-small-cell lung cancer. J Clin Oncol 2016;34:3375-82.

30. Sundaresan TK, Sequist LV, Heymach JV, et al. Detection of T790M, the acquired resistance EGFR mutation, by tumor biopsy versus noninvasive blood-based analyses. Clin Cancer Res 2016;22:1103-10.

31. Fischer JC, Niederacher D, Topp SA, et al. Diagnostic leukapheresis enables reliable detection of circulating tumor cells of nonmetastatic cancer patients. Proc Natl Acad Sci U S A 2013;110:16580-5.

32. Coumans FAW, Ligthart ST, Uhr JW, et al. Challenges in the enumeration and phenotyping of CTC. Clin Cancer Res 2012;18:5711-8.

33. de Wit S, van Dalum G, Lenferink ATM, et al. The detection of EpCAM+ and EpCAM- circulating tumor cells. Sci Rep 2015;5:12270-9.

34. Ilié M, Szafer-Glusman E, Hofman V, et al. Detection of PD-L1 in circulating tumor cells and white blood cells from patients with advanced non-small-cell lung cancer. Ann Oncol 2018;29:193-9. 
Table S1 Characteristics of advanced non-small cell lung cancer patients treated with tyrosine kinase inhibitors

\begin{tabular}{|c|c|c|c|c|c|c|c|c|}
\hline Patient & Gender & $\begin{array}{l}\text { Therapy } \\
\text { line }\end{array}$ & $\begin{array}{l}\text { Treatment given } \\
\text { at CTC date }\end{array}$ & Mutation present & $\begin{array}{l}\text { Response to } \\
\text { Rx na CTC }\end{array}$ & $\begin{array}{c}\text { CTC } \\
\text { detected }\end{array}$ & $\begin{array}{c}\text { CTC }>1 \text { or } \\
0-1\end{array}$ & Date CTC \\
\hline 1 & Male & 1 & Erlotinib & EGFR E746_A750del & PR & $\mathrm{CTC}=0$ & CTC $=0-1$ & May 2014 \\
\hline 3 & Female & 1 & Erlotinib & EGFR L858R and PIK3CA E542K & PR & $\mathrm{CTC}=0$ & $\mathrm{CTC}=0-1$ & May 2016 \\
\hline 4 & Male & 1 & Erlotinib & EGFR G719S and E709A & PR & $\mathrm{CTC}=0$ & СТC $=0-1$ & September 2013 \\
\hline 6 & Male & 1 & Erlotinib & EGFR E746_A750del, KIT M425K & PR & $\mathrm{CTC}=0$ & CTC $=0-1$ & January 2016 \\
\hline 7 & Female & 2 & Erlotinib & EGFR E746_A750del & PR & $\mathrm{CTC}=0$ & CTC $=0-1$ & March 2014 \\
\hline 8 & Male & 1 & Erlotinib & EGFR L858R & $\mathrm{PD}$ & $\mathrm{CTC}=0$ & CTC $=0-1$ & May 2015 \\
\hline 9 & Female & 1 & Erlotinib & EGFR G719A and S768I & $\mathrm{PD}$ & $\mathrm{CTC}=0$ & CTC $=0-1$ & November 2015 \\
\hline 13 & Female & 2 & Afatinib & EGFR E709A, EGFR G719A & PR & $\mathrm{CTC}=0$ & CTC $=0-1$ & September 2015 \\
\hline 14 & Female & 3 & Afatinib & EGFR L858R and EGFR T790M & SD & $\mathrm{CTC}=0$ & CTC $=0-1$ & February 2014 \\
\hline 15 & Male & 3 & Afatinib & EGFR D770-N7711insSVD & SD & $\mathrm{CTC}=0$ & СТC $=0-1$ & March 2014 \\
\hline 16 & Female & 2 & Osimertinib & EGFR G719S en T790M & SD & $\mathrm{CTC}=0$ & CTC $=0-1$ & February 2016 \\
\hline 17 & Female & 1 & Dabrafenib & BRAF V600E & PR & $\mathrm{CTC}=0$ & CTC $=0-1$ & September 2013 \\
\hline 18 & Male & 2 & $\begin{array}{l}\text { Dabrafenib/ } \\
\text { trametinib }\end{array}$ & BRAF V600E & PR & $\mathrm{CTC}=0$ & CTC $=0-1$ & May 2014 \\
\hline 19 & Female & 2 & $\begin{array}{l}\text { Dabrafenib/ } \\
\text { trametinib }\end{array}$ & BRAF V600E & PR & $\mathrm{CTC}=0$ & CTC $=0-1$ & December 2014 \\
\hline 34 & Female & 2 & Brigatinib & ALK S1206A & $\mathrm{CR}$ & CTC $\geq 1$ & CTC $=0-1$ & February 2015 \\
\hline 27 & Female & 1 & Erlotinib & EGFR E746_A750del & PD & CTC $\geq 1$ & $\mathrm{CTC} \geq 2$ & January 2016 \\
\hline 28 & Female & 2 & Afatinib & EGFR p.L747_749del & PD & $\mathrm{CTC} \geq 1$ & $\mathrm{CTC} \geq 2$ & September 2013 \\
\hline 30 & Female & 6 & Rociletinib & EGFR E709A en G719s & PD & $\mathrm{CTC} \geq 1$ & $\mathrm{CTC} \geq 2$ & January 2016 \\
\hline 31 & Female & 1 & Dabrafenib & BRAF V600E & PR & CTC $\geq 1$ & CTC $\geq 2$ & November 2015 \\
\hline 32 & Female & 1 & Dabrafenib & BRAF V600E & PD & СTC $\geq 1$ & CTC $\geq 2$ & January 2014 \\
\hline 33 & Male & 1 & Vemurafenib & BRAF V600E & PD & CTC $\geq 1$ & $\mathrm{CTC} \geq 2$ & October 2014 \\
\hline 35 & Female & 1 & Crizotinib & ALK rearrangement $35 \%$, IHC positive & PD & CTC $\geq 1$ & CTC $\geq 2$ & July 2015 \\
\hline 36 & Female & 1 & Crizotinib & ALK rearrangement, $46 \%$, IHC positive & PD & CTC $\geq 1$ & CTC $\geq 2$ & January 2015 \\
\hline 37 & Female & 1 & Crizotinib & $\begin{array}{l}\text { ALK rearrangement } 74 \% \text {, IHC positive, } \\
\text { ROS1 rearrangement } 22 \%\end{array}$ & PD & СТC $\geq 1$ & СТC $\geq 2$ & February 2015 \\
\hline 38 & Male & 3 & Alectinib & ALK rearrangement $41 \% \mathrm{IHC}$ negative & PD & CTC $\geq 1$ & СТC $\geq 2$ & March 2015 \\
\hline
\end{tabular}

Response was based on the RECIST 1.1 criteria and denoted as progressive disease (PD), stable disease (SD), partial response $(\mathrm{PR})$, complete response (CR) depending on the tumor size changes after therapy and the development of new lesions. IHC, immunohistochemistry; ND, not done; CTC, circulating tumor cell. 
Table S2 Characteristics of advanced non-small cell lung cancer patients stratified for the presence of circulating tumor cells (CTC)

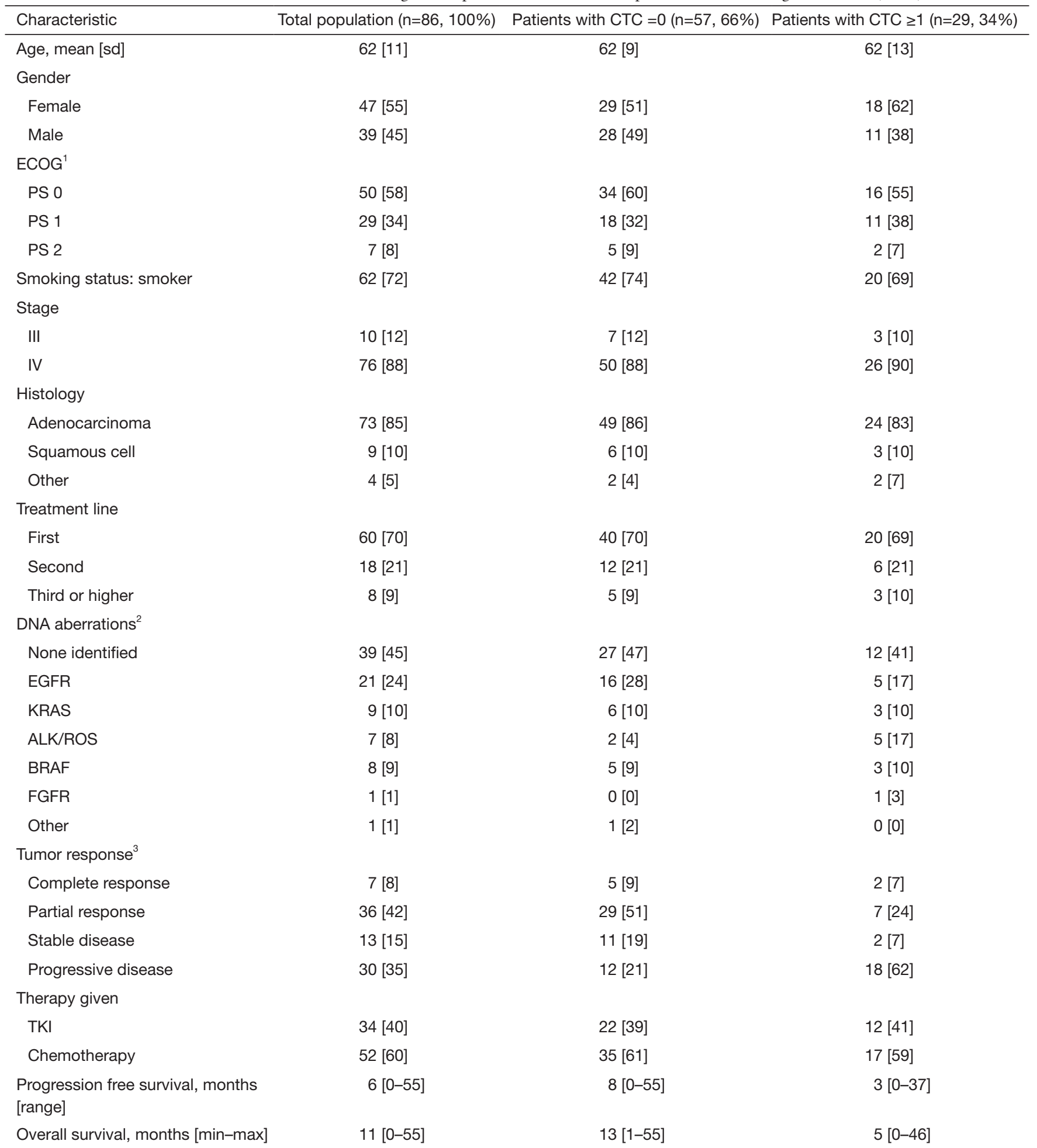

${ }^{1}$, Eastern Cooperative Oncology Group Performance Score; ${ }^{2}$, molecular profiling performed in tissue biopsy of adenocarcinoma using a NGS multigene panel including TKI-targetable mutations, FISH for ALK, ROS1 and RET rearrangements and IHC for ALK expression on adenocarcinoma. Squamous cell were tested for FGFR1 amplifications; ${ }^{3}$, Revised Response Evaluation Criteria In Solid Tumor v1.1; *, covariable was significantly different between treatment groups $(\mathrm{P}<0.05)$. IHC, immunohistochemistry; TKI, tyrosine kinase inhibitor. 